\title{
Climate change and the demise of Minoan civilization
}

\author{
A. A. Tsonis ${ }^{1}$, K. L. Swanson ${ }^{1}$, G. Sugihara ${ }^{2}$, and P. A. Tsonis ${ }^{3}$ \\ ${ }^{1}$ Department of Mathematical Sciences, Atmospheric Sciences Group, University of Wisconsin-Milwaukee, Milwaukee, \\ WI 53201, USA \\ ${ }^{2}$ Scripps Institution of Oceanography, University of California San Diego, 9500 Gilman Drive, La Jolla, \\ CA 92093-0202, USA \\ ${ }^{3}$ Department of Biology, University of Dayton, Dayton, OH 45469, USA
}

Received: 7 April 2010 - Published in Clim. Past Discuss.: 12 May 2010

Revised: 12 July 2010 - Accepted: 13 August 2010 - Published: 24 August 2010

\begin{abstract}
Climate change has been implicated in the success and downfall of several ancient civilizations. Here we present a synthesis of historical, climatic, and geological evidence that supports the hypothesis that climate change may have been responsible for the slow demise of Minoan civilization. Using proxy ENSO and precipitation reconstruction data in the period 1650-1980 we present empirical and quantitative evidence that El Nino causes drier conditions in the area of Crete. This result is supported by modern data analysis as well as by model simulations. Though not very strong, the ENSO-Mediterranean drying signal appears to be robust, and its overall effect was accentuated by a series of unusually strong and long-lasting El Nino events during the time of the Minoan decline. Indeed, a change in the dynamics of the El Nino/Southern Oscillation (ENSO) system occurred around $3000 \mathrm{BC}$, which culminated in a series of strong and frequent El Nino events starting at about $1450 \mathrm{BC}$ and lasting for several centuries. This stressful climatic trend, associated with the gradual demise of the Minoans, is argued to be an important force acting in the downfall of this classic and long-lived civilization.
\end{abstract}

\section{Introduction}

The Minoan civilization was a prominent Bronze Age society which flourished from approximately 2700 to $1450 \mathrm{BC}$ on Crete, Greece (Fig. 1). The Minoans developed splendid architecture, a complex language, and a written script that

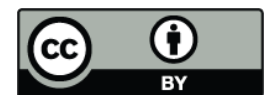

Correspondence to: A. A. Tsonis (aatsonis@uwm.edu) is still not understood. They built a significant naval power and coexisted with neighboring civilizations as the dominant influence in the region (apparently without being significantly threatened). Contact with Egypt and Mesopotamia influenced their culture, as the Minoan civilization evolved to become the forerunner of Greek civilization; thus Minoan society is generally regarded as the first European civilization. Following its regional predominance for more than a millennium, Minoan civilization slowly withered until it disappeared around $1200 \mathrm{BC}$.

There are essentially two main theories that have been invoked to explain the demise of Minoan civilization, but neither matches the observed gradual decline that took place. One is the explosion of the volcano in Thera (Santorini) and the other is invasion and occupation by the Mycenaeans. The former was suggested by Marinatos (1939). This catastrophic theory argues that earthquakes destroyed the palaces, tsunamis obliterated the fleet and peers of the Minoans, and the volcanic ash of Thera covered the whole island destroying crops and killing animals. This view was initially supported by geologists who agreed that the Thera eruption was of a colossal scale, and such effects were possible. However, in 1987 studies conducted at the Greenland ice cap dated frozen ash from the Thera eruption and concluded that it occurred in $1645 \mathrm{BC}$ with an estimated standard deviation of \pm 7 yr (Hammer et al., 1987). This result has been considered many times since 1987. For example Friedrich et al. (2006) found a branch of olive tree buried alive in tephra in Santorini and were able to place the eruption with $95 \%$ confidence in the range 1627-1600 BC (see also Friedrich, 2009 and references therein). Manning et al. (2006) dated 127 radio-carbon samples from Akrotiri, Crete and other Aegean sites spanning a period from 1700 to $1400 \mathrm{BC}$ and dated the eruption

Published by Copernicus Publications on behalf of the European Geosciences Union. 


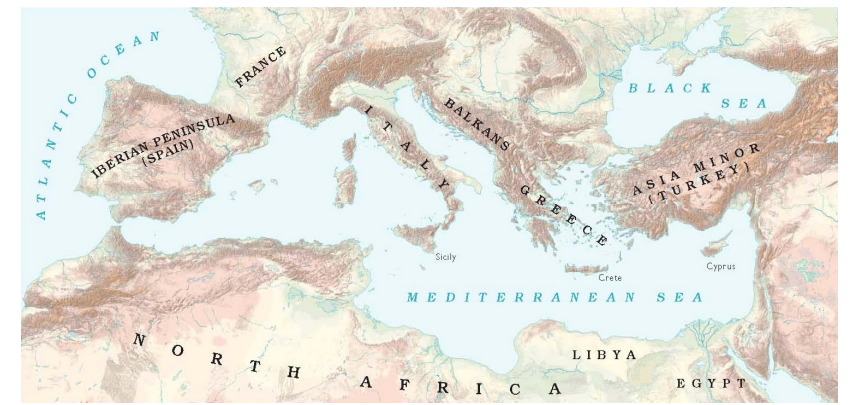

Fig. 1. A map of the Mediterranean region. This material originated on the Interactive Ancient Mediterranean Web site (http: //iam.classics.unc.edu). It has been copied, reused or redistributed under the terms of IAM's fair use policy. Copyright 1998, Interactive Ancient Mediterranean.

between 1660 and 1613 with a 95\% confidence. Vinther et al., 2006 through a synchronized dating of three Greenland ice cores estimated the eruption at $1642 \pm 5 \mathrm{yr}$ BC. The consistency of all these studies leaves liitle doubt about the date of the eruption. They all place the event several hundred years before the destruction of the Minoan palaces which took place around $1450 \mathrm{BC}$ and the final disappearance of Minoans around $1200 \mathrm{BC}$.

Minoan society faced many problems and physical disasters throughout its history but it rebounded to elevate its culture to high levels. So why did it not recover after the destruction of $1450 \mathrm{BC}$ ? An explanation is provided by the hypothesis that an invasion by the Mycenaeans was responsible for the destruction of the palaces and their subsequent occupation contributed to the demise of Minoan civilization. However, archeological evidence to support this idea is either contradictory or lacking. For example, skeletal remains consistent with an invasion pattern have never been found (Callender, 1999). Indeed in the palaces the dead were neatly buried in well preserved burial sites, a pattern inconsistent with an invasion scenario. The fact that the Mycenaeans did not establish themselves in nearby and more vulnerable Crete as they did in mainland Greece is also not consistent with ambitious military conquest, even though Mycenaean culture was clearly influential in mainland Greece at this time. Questions regarding the demise of the Minoan civilization remain unanswered as the historical and physical records fail to provide definitive answers.

\section{The climate connection}

Climate has played a significant role in the disappearance of several cultures on Earth. A recent study (Sandweis et al., 2009), for example, reviews evidence of how environmental changes induced by earthquakes and El Nino flooding contributed to the demise of the early Supe settlements in Peru. Another example is the disappearance of the Mayans.
Around 800 AD, the Mayans were at the peak of civilization with a population of about 15 million occupying the area from Mexico's Yucatán peninsula to Honduras, before they ultimately and rather suddenly disappeared. In addition to hypotheses concerning epidemic disease as the agent, evidence has emerged that a long period of dry climate, punctuated by three intense droughts, may have contributed to the end of Mayan society (Haug et al., 2003). Here we examine multiple and consistent evidence to suggest that climate played a central role in the downfall of Minoan civilization and that the ultimate mechanism was a fundamental change in the dynamics of El Nino/ Southern Oscillation (ENSO).

ENSO is a phenomenon that takes place in the Pacific Ocean. During normal conditions the westward surface winds in the tropical Pacific sweep and accumulate over time warm surface water to the west. This leaves the surface eastern tropical Pacific with colder upwelling water. Thus during normal conditions (often referred as La Nina) there are cold surface temperatures in the eastern Pacific and warm in the western Pacific. The continual accumulation of warm water in the west increases the surface elevation and eventually the warm pool of surface water sloshes back to cover all tropical Pacific. We now have an El Nino, which is characterized by a large warm spot over the tropical Pacific Ocean. This surface warming is large enough to interact with the atmosphere, which is then modified and brings significant weather changes all over the world. These ENSO teleconnections are established via complex mechanisms involving El Nino and its effect on the North Pacific area, and the subsequent result of this effect on the wave structure of northern hemisphere circulation. The north Atlantic and the stratosphere may also be key players in establishing El Nino teleconnections (Mokhov and Smirnov, 2006; Ineson and Scaife, 2009).

Figure 2 shows the correlation between the cold season (DJF) Nino3 index (Mann et al., 2000) and the seasonal (DJF) precipitation reconstruction over Europe (Pauling et al., 2006; Mitchell and Jones, 2005). The Nino3 data cover the period 1650-1980 AD and the gridded precipitation data the period 1500-2000 AD. The correlation is based on the data in the common period 1650-1980 AD. Most correlations are small but what is important (especially with nonlinear interactions such as ENSO and precipitation teleconnections) is emerging patterns. Here a very coherent and nonrandom spatial structure is evident suggesting a significant precipitation signal of El Nino over Europe. Given the large sample size of the time series being correlated and the fact that the precipitation field has very little spatial correlation, it is unlikely that such a coherent pattern will emerge from a random process. In fact, we have repeated this analysis by correlating a randomized version of the Mann et al. (2000) Nino3 index to the proxy precipitation field and we found that the coherency of the pattern observed in Fig. 2 is destroyed and that the correlations are smaller by a factor of about 2-3 (Fig. 3). The map in Fig. 2 indicates drier conditions over Northern Africa and part of the Mediterranean (a 


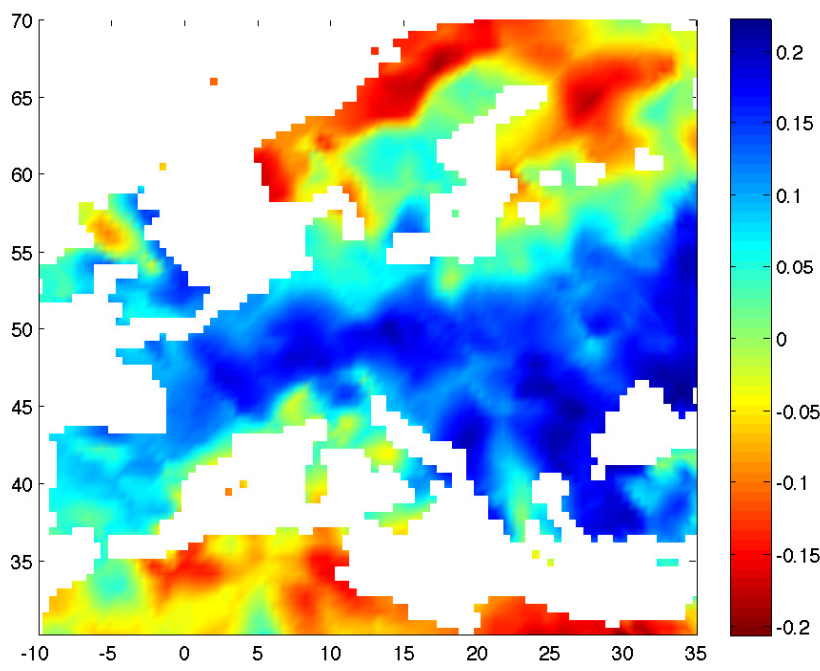

Fig. 2. Correlation between the cold season (DJF) Nino3 index (Mann et al., 2000) and the seasonal (DJF) precipitation reconstruction over Europe (Pauling et al., 2006; Mitchell and Jones, 2005). Red indicates negative correlations corresponding to drier conditions and blue positive correlations associated with wetter conditions. While correlations may be weak the spatial structure is nevertheless non-random.

direct result of the cyclone track shifting northward during El Nino; Bronnimann, 2007), wetter conditions over most of Europe and drier conditions in Scandinavia. Even though it is only represented by two grid points, Crete is located in the drier belt. For the area of Crete we find that the fractional change of precipitation between El Nino and La Nina years to be around $10 \%$. This result, as well as the correlation structure in Fig. 2, is consistent with results using instrumental rainfall station data in the period 1880-1980 (Fraedrich and Muller 1992; Bronnimann, 2007).

The El Nino signal on precipitation on Crete appears to be weak but as confirmed by modeling results it is a robust phenomenon and as we will see below during the time of the Minoans this signal may have been 2-3 times stronger. Figure 4 is based on model simulations and also indicates that by and large precipitation in the area of interest is reduced during El Nino events and increased during La Nina events. Note that the El Nino OND and JFM maps are in very good agreement with the spatial structure in Fig. 2 which is reversed during La Nina years (from Bronnimann, 2007). This consistency suggests that the El Nino signal in the area of Crete is robust. Parenthetically we point out the exceptional pattern on Cyprus which adds to our argument about climate effects in the region. Cyprus even though relatively close to Crete appears to be wetter during El Nino years. This is clear in Fig. 2 and in the model simulation (Fig. 4). Interestingly, at the time when the Minoans were in decline the Cypriots were apparently not suffering the same fate. This special case is reassuring, however it raises the question as

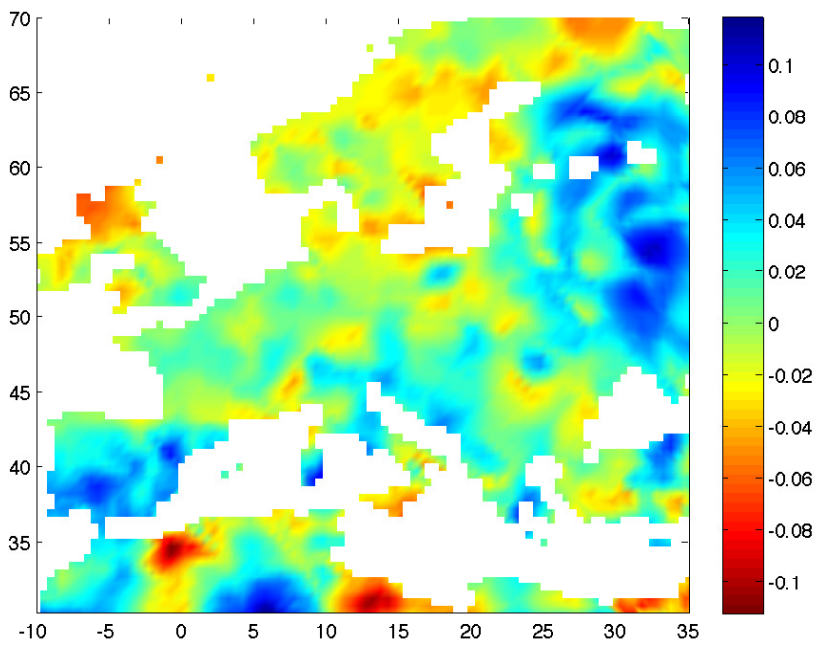

Fig. 3. Same as Fig. 2 but now we correlate a randomized version of the Mann et al. (2000) Nino3 index to the proxy precipitation field. Clearly the coherence observed in the pattern in Fig. 2 is destroyed and moreover the correlations are smaller by a factor of about 2-3.

to whether during the period from 1450 to $1200 \mathrm{BC}$ El Nino activity was sufficiently unusual, broad, and long-lasting to produce a strong enough signal to cause the gradual decline of the Minoans.

A recent study (Moy et al., 2002) documented the variability of El Nino/Southern Oscillation activity at millennial timescales during the Holocene epoch (Fig. 5; adapted from Moy et al., 2002). This is a proxy record based on the distribution of inorganic clastic laminae in a core retrieved from Lake Laguna Pallcacocha in Ecuador. The laminae are deposited during ENSO-driven episodes of alluvial deposition in the Laguna Pallcacocha drainage basin. These laminae are mixed with dark-colored organic-rich silt. The surface of the core sections was scanned and the intensity of the red color was used to generate the proxy record. In general higher intensity values correspond to El Nino and lower values to La Nina. This record has been extensively and rigorously analyzed using modern time series analyses (Moy et al., 2002; Tsonis, 2008; Wang and Tsonis, 2008) and the results suggest a change in the dynamics at around 3000 BC. It appears that around that time a bifurcation occurred in the ENSO system causing the attractor of the underlying dynamical system to become higher dimensional with less stable behavior (Tsonis, 2008). As a consequence the system switched from a dynamics where the normal La Nina condition was the dominant mode to a dynamics where El Nino events became more frequent and stronger. Changes in boreal summer insolation or slow changes in ocean dynamics (which are known to be affected during interglacial events) have been suggested as possible mechanisms for this bifurcation (Tsonis, 2008). This scenario is consistent with geoarchaeological evidence from Peru, which also suggests 


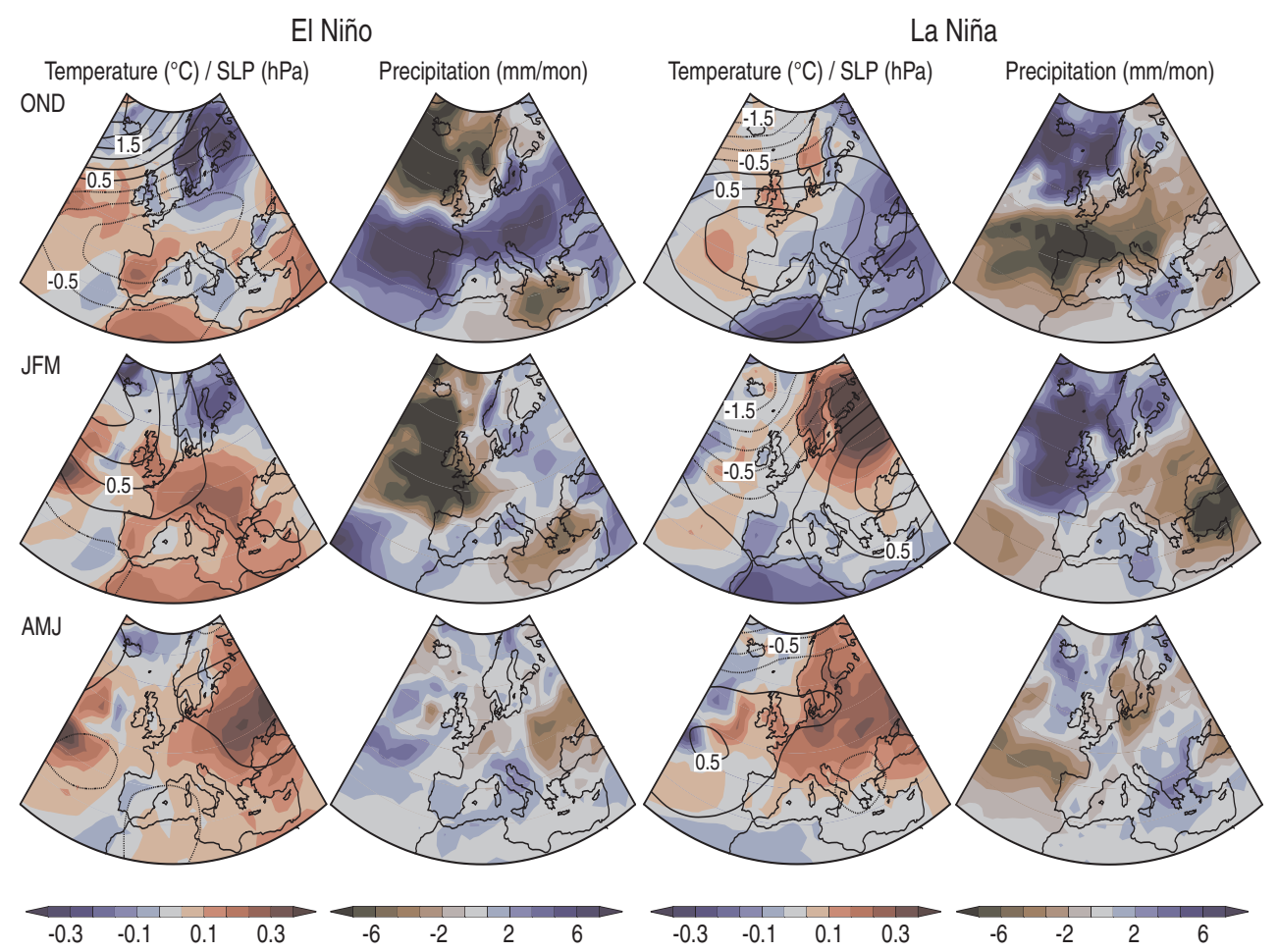

Fig. 4. Anomaly fields of temperature, SLP (contours), and precipitation for strong El Nino and strong La Nina events in 540 years of the control run b30.009 of version 3 of the Community Climate System Model (CCSM3) for different seasons. Strong events are defined when the September-to-February average of Nino3.4 index was outside 1 standard deviation. In the precipitation maps blue corresponds to above normal precipitations and brown to below normal precipitation. In the temperature maps blue indicates below normal values and red above normal values. Consistent with observations, this simulation suggests that by and large the area surrounding Crete will experience drier and warmer conditions during El Nino (from Bronnimann, 2007; Figure courtesy of Stefan Bronnimann).

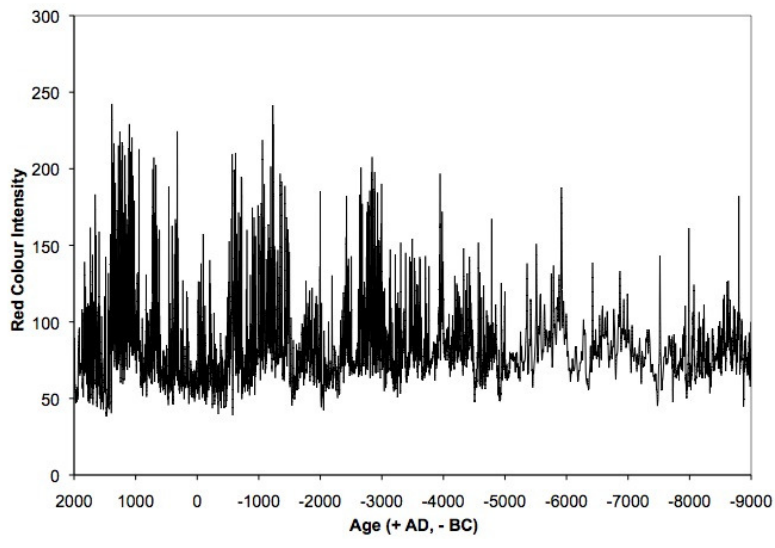

Fig. 5. El Nino proxy reconstruction from Laguna Pallcacocha, Ecuador. High red color intensity indicates an El Nino event. At about $1500 \mathrm{BC}$ a series of strong El Nino events begins that lasts for centuries (adapted from Moy et al., 2002).

absence of El Nino before $5000 \mathrm{BP}(3000 \mathrm{BC})$ and its onset after that (Sandweis et al., 1996). Additional support for the Ecuador ENSO proxy record is provided by a recent study of hurricane events (Donnelly and Woodruff, 2007). It is well known that ENSO affects hurricane activity in the At- lantic Ocean and that this activity is reduced during El Nino years. That study shows that a proxy record of hurricane activity over the past 5000 years obtained from sediment cores in Vieques, Puerto Rico is well correlated with the Ecuador ENSO proxy record. In addition, precipitation inferred from sediment cores from Lake Ossa in West Cameroon (an area where ENSO's effect on precipitation is well known) also correlates well with the Ecuador ENSO proxy record.

According to Fig. 5, a series of intense El Nino events (high red color intensity) begins at about $1450 \mathrm{BC}$ that will last for centuries. In that period normal (La Nina) conditions have but disappeared. For comparison, the very strong 1998 El Nino event scores 89 in red color intensity. During the time when the Minoans were fading, El Nino events reach values in red color intensity over 200. Figure 6 shows a comparison between the two proxies for ENSO used here. It shows El Nino frequency in a 50-year moving window. The frequency of events for the Mann et al. (2000) record is estimated by the number of El Nino events in a 50-year window where an El Nino event is defined when Mann's El Nino index is greater than 1 standard deviation. The Moy et al. (2002) record is a direct measure of El Nino frequency. The idea behind Fig. 6 is that if the correlation pattern in 

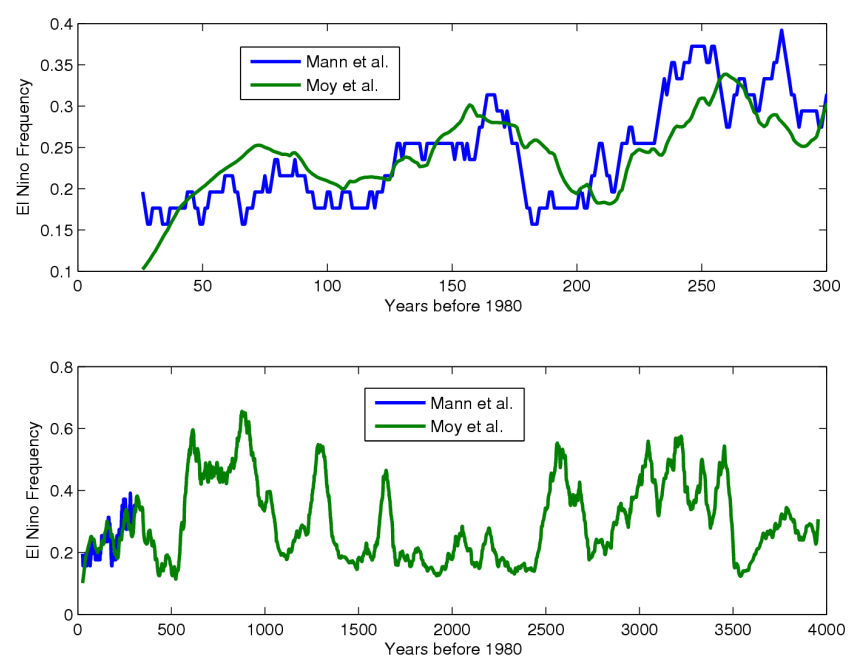

Fig. 6. Comparison between the two ENSO proxies used here during common years. The agreement between the two records is rather good. Moreover, the bottom panel indicates that the intensity of the stretch of El Nino events starting at about $1450 \mathrm{BC}$ is much larger than that observed in the 350 years before present. This would suggest that the El Nino signal may have been much stronger at the time of the Minoans. The labeling of the $\mathrm{x}$-axis is as such because the common interval of the two proxies is 1650-1980 AD and the window is 50 years.

Fig. 2 is based on one proxy data set (Mann et al., 2000) and the onset of frequent and strong El Nino events at the time of the demise is based on another proxy record (Moy et al., 2002), then in order to have a closure those two proxies should be consistent where they overlap.

The top panel shows that the two proxies are in good agreement and the bottom panel that the El Nino events in the ENSO proxy starting at about $1450 \mathrm{BC}$ are much stronger than those in the recent three hundred years (by a factor between two and three). This will indicate that the El Nino signal may have been much stronger at the time of the Minoans. Thus, it is highly probable that the area of Crete experienced drier conditions from 1450 to $1200 \mathrm{BC}$ and even later. For communities that strongly depended on water and agriculture in order to survive, the cumulative effect of these drier conditions could have been devastating and may have led to a slow decline bringing the population below a critical threshold that will allow it to exist and thrive. The above results and observations are also supported by an $\mathrm{O}^{18}$ analysis (Magill et al., 2005; Rosenmeier et al., 2006) of a core obtained from the Limnes depression, a small sinkhole located within the Akrotiri Peninsula, Crete (close to the palace of Knossos and other important outlets of the Minoans). This analysis indicates that wetter conditions during the middle Holocene were followed by drier conditions and that around $1450 \mathrm{BC}$ a long stretch of drier conditions commenced ending around $1200 \mathrm{BC}$. The same record shows that at the onset of strong and frequent El Nino events around $1000 \mathrm{AD}$ $(\sim 1000 \mathrm{yr}$ BP) the area again enters drier conditions which peak at about $1500 \mathrm{AD}(\sim 500 \mathrm{yr} \mathrm{BP})$ when the dominance of El Nino ends. This is consistent with our hypothesis. Additional sediment support for drier conditions after $1450 \mathrm{BC}$ is provided by a pollen core obtained from Lake Kournas in Crete. In that core Tilia (a temperate European tree) pollen, while present before 1400 , has but disappeared in the period 1400-1000 BC. This suggests that annual drought levels reached levels beyond which the tree could not survive (Moody, 2005). Indeed, the tree does not anymore grow naturally in Crete.

\section{Conclusions}

We have presented a synthesis of historical, climatic, and geologic evidence which supports the hypothesis that climate change instigated by an intense El Nino activity contributed to the demise and eventual disappearance of the Minoan civilization. The North Atlantic Oscillation (NAO) in its positive phase may also bring dry conditions in the Mediterranean (Luterbacher and Xoplaki, 2003). This effect, however, cannot be assessed in the second millennium BC as no proxy NAO data extend that far. Nevertheless, El Nino has been linked to North Atlantic and NAO activity (Ineson and Scaife, 2009; Huang et al., 1998; Wang et al., 2009; OrtizBevia et al., 2010) and this possibility could have accentuated the dry conditions. Climate change and its associated effects will always influence our lives. While nobody anymore expects any civilization to get extinct because of climate, it is becoming clear that convergent events such as earthquakes and volcanic activity in synergy with climate anomalies may produce significant stress to contemporary populations vis-àvis their social and economic development (Moseley, 1999). It is thus important that we understand how the evolutionary trajectory of early civilizations was disrupted and that even today we may not be completely immune to hazardous stress induced by natural catastrophes.

Acknowledgements. We thank Elena Xoplaki for her suggestions and A. Gershunov, W. Friedrich, and K. Anchukaitis for their helpful comments.

Edited by: C. Barbante

\section{References}

Bronnimann, S.: Impact of El Nino-Southern oscillation on European climate, Rev. Geophys 45, RG3003, doi:10.1029/2006RG000199, 2007.

Callender, G.: The Minoans and the Mycenaeans: Aegean Society in the Bronze Age, Oxford University Press, UK, 1999.

Donnelly, J. P. and Woodruff, J. D.: Intense hurricane activity over the past 5000 years controlled by El Nino and the West African monsoon, Nature, 447, 465-468, doi:10.1038/nature05834, 2007. 
Fraedrich, K. and Muller, K.: Climate anomalies in Europe associated with ENSO extremes, Int. J. Climatol., 12, 25-31, 1992.

Friedrich, W. L., Kromer, B., Friedrich, M., Heinemeier, J., Pfeiffer, T., and Talamo, S.: Santorini eruption radiocarbon dated to $1627-1600$ BC, Science, 312, 548, doi:10.1126/science.1125087, 2006.

Friedrich, W. L.: Santorini Volcano - natural history - mythology. Aarhus University Press, Denmark, 2009.

Hammer, C. U., Clausen, H. B., Friedrich, W. L., and Tauber, H.: The Minoan eruption of Santorini in Greece dated to 1645 BC? Nature, 328, 517-519, 1987.

Haug, G. H., Gunther, D., Peterson, L. C., et al.: Climate and the Collapse of Mayan Civilization, Science, 299, 1731-1735, 2003.

Huang, J.-P., Higushi, K., and Shabbar, A.: The relationship between The North Atlantic Oscillation and El Nino-Southern Oscillation, Geophys. Res. Lett., 25, 2701-2719, 1998.

Ineson, S. and Scaife, A. A.: The role of stratosphere in the European climate response to El Nino, Nat. Geosci., 2, 32-36, 2009.

Luterbacher, J. and Xoplaki, E.: 500-year winter temperature and precipitation variability over the Mediterranean area and its connection to large-scale atmospheric circulation, in: Mediterranean Climate: Variability and Trends, edited by: Bolle, H., Springer, Berlin, 133-153, 2003.

Magill, C. R., Rosenmeier, M. F., Cavallari, B. J., Curtis, J. H., and Weis, H.: Reconstruction of Holocene climate variability within the central Mediterranean using lake sediments from Akrotiri Peninsula, Crete, in: Abstract Volume of the Fall Meeting of the American Geophysical Union, 5-9 December 2005, San Francisco, California, 2005.

Mann, M. E., Bradley, R. S., and Hughes, M. K.: Long-term variability in the El Nino Southern Oscillation and associated teleconnections, in: El Nino and the Southern Oscillation: multiscale variability and its impacts on natural ecosystems and society, edited by: Diaz, H. F. and Markgraf, V., Cambridge University Press, 321-372, 2000.

Manning, S. W., Ramsey, C. B., Kutschera, W., et al.: Chronology for the Aegean late Bronze Age 1700-1400 BC, Science, 312, 565-569, 2006.

Marinatos, S.: The Volcanic Destruction of Minoan Crete, Antiquity, 13, 425-439, 1939.

Mitchell, T. D. and Jones, P. D.: An improved method of constructing a database of monthly climate observations and associated high-resolution grids, Int. J. Climatol., 25, 693-712, 2005.
Mokhov, I. I. and Smirnov, D. A.: El Nino-Southern Oscillation drives North Atlantic Oscillation as revealed with nonlinear techniques from climatic indices, Geophys. Res. Lett., 33, L033708, doi:10.1029/2005GL024557, 2006.

Moseley, M. E.: Convergent catastrophe: Past patterns and future implications of collateral natural disasters in the Andes, in: The Angry Earth, edited by: Oliver-Smith, A. and Hoffman, S. M., Routledge, New York, 59-71, 1999.

Moy, C. M., Seltzer, G. O., Rodbell, D. T., and Anderson, D. M.: Variability of El Nino/Southern Oscillation activity at millennial timescales during the Holocene epoch, Nature, 420, 162-165, 2002.

OrtizBevia, M., Perez-Gonzales, I., Alvarez-Garcia, F., and Gershunov, A.: Nonlinear estimation of El Nino impact on the North Atlantic winter, J. Geophys. Res., in press, 2010, .

Pauling, A., Luterbacher, J., Casty, C., and Wanner, H.: Five hundred years of gridded high resolution precipitation reconstructions over Europe and the connection to large-scale circulation, Clim. Dynam., 26, 387-405, 2006.

Rosenmeier, M. F., Magill, C. R., and Curtis, J. H.: Lake sediment records of Holocene climate variability within western Crete, Cornell University Dendrochronology and Archaeology Conference in Honor of Peter Ian Kuniholm, 3-5 November 2006, Ithaca, New York, 2006.

Sandweiss, D. H., Richardson, J. B., Reitz, E. J., et al.: Geoerchaeological evidence from Peru for a 5000 years BP onset of El Nino, Science, 273, 1531-1533, 1996.

Sandweis, D. H., Solis, R. S., Moseley, M. E., Keefer, D. K., and Ortloff, C. R.: Environmental change and economic development in coastal Peru between 5,800 and 3,600 years ago, Proc. Natl. Acad. Sci. USA, 106, 1359-1363, doi/10.1073/pnas.0812645106, 2009.

Tsonis, A. A.: Dynamical changes in the ENSO system in the last 11000 years, Clim. Dynam., 33, 1069-1074, doi:10.1007/s00382-008-0469-4, 2008.

Vinther, B. M., Clausen, H. B., Johnsen, S. J., et al.: A synchronized dating of three Greenland ice cores throughout the Holocene, J. Geophys. Res., 111, D13102, doi:10.1029/2005JD006921, 2006

Wang, G., Swanson, K. L., and Tsonis, A. A.: The pacemaker of major climate shifts, Geophys. Res. Lett., 36, L07708, doi:10.1029/2008GL036874, 2009.

Wang, G. and Tsonis, A. A.: On the variability of ENSO at millennial timescales, Geophys. Res. Lett., 35, L17702, doi:10.1029/2008GL035092, 2008. 